\title{
COVID-19. The US Perspective, Atlanta
}

\author{
Eltayeb Mohamed Ahmed ${ }^{1}$ and Edward Chen ${ }^{1}$ \\ ${ }^{1}$ Emory University
}

September 11, 2020

\begin{abstract}
Abstract: Background: The COVID-19 pandemic in late 2019 quickly stretched health care system across the globe. Mortalities, shortages in health care system capacity, and lack of experience in similar circumstances required innovation in the way health care is delivered. Health care systems changed operating schedules, staff work pattern, and how patients are cared for. The effects of these changes reached patients, staff and training in different ways. Methods: We search the Pubmed and EMBASE for articles related to COVID-19. We also searched local e-mails and information provided to staff during the pandemic Results: The COVID-19 pandemic affected organisations, patients and staff. The organisation and staff had to adapt to the times to provide a safe and appropriate service to our patients. Conclusion: The pandemic challenged and changed the way we work as health care providers, and how we train the future surgeons. Changes in the system was effective.
\end{abstract}

Title: COVID-19. The US Perspective, Atlanta

Short running title: COVID-19. The US Perspective, Atlanta

Authors:

Eltayeb Mohamed Ahmed, M.D ${ }^{1}$; Edward P. Chen, M.D ${ }^{1}$

Authors' affiliation:

Division of Cardiothoracic Surgery, Department of Surgery, Emory School of Medicine, Atlanta, Georgia, USA.

\section{Authors contact details:}

1) Eltayeb Mohamed Ahmed

eltayeb.kamal@gmail.com

2) Edward P. Chen

edward.p.chen@emory.edu

Corresponding Author:

Professor Edward P. Chen

Address: Division of Cardiothoracic Surgery, Department of Surgery, Emory School of Medicine, Atlanta, Georgia, USA.

e-mail: edward.p.chen@emory.edu

Telephone: 001404.778 .3484

Funding: No funding was required for this work 


\section{Conflict of interest: The authors have no conflict of interest in relation to this work}

\section{Keywords:}

Pandemic, Thoracic Surgery, Public health, Education, Review

\section{Abstract:}

\section{Background:}

The COVID-19 pandemic in late 2019 quickly stretched health care system across the globe. Mortalities, shortages in health care system capacity, and lack of experience in similar circumstances required innovation in the way health care is delivered. Health care systems changed operating schedules, staff work pattern, and how patients are cared for. The effects of these changes reached patients, staff and training in different ways.

\section{Methods:}

We search the Pubmed and EMBASE for articles related to COVID-19. We also searched local e-mails and information provided to staff during the pandemic

\section{Results:}

The COVID-19 pandemic affected organisations, patients and staff. The organisation and staff had to adapt to the times to provide a safe and appropriate service to our patients.

\section{Conclusion:}

The pandemic challenged and changed the way we work as health care providers, and how we train the future surgeons. Changes in the system was effective.

\section{Introduction:}

Late in 2019 a pneumonia-causing virus, later identified as COVID-19, has been identified in Wuhan, China ${ }^{(1)}$. Shortly, the virus spread to 19 countries and a world health emergency was declared as it reached a pandemic status ${ }^{(2)}$. It was the news reports from Italy of a healthcare system stretched beyond its capacity, soaring fatalities, and strict governmental interventions to limit the spread that alerted most European and North American countries. The first reported case in the United States was reported on the $22^{\text {nd }}$ of January ${ }^{(3)}$. As it became obvious that the disease would spread in the US, health care systems started developing strategies to combat the spread of the disease, acquiring resources to deal with unprecedented demands, and to train staff to protect themselves and provide care for a special subset of patients.

\section{How did the organisation adapt to the pandemic?}

It became immediately evident that communication between the organisation leadership and staff is key and a daily e-mail COVID-19 update was established. It provided information about the number of cases in the system, changes in policy, advice for staff on seeking support both mentally and physically. The daily updates provided reassurance to the working force and a reliable source to be informed; they were greatly appreciated by both clinical and non-clinical staff alike. The daily communication was particularly appreciated with regard to the availability of Personal Protective Equipment (PPE), as concerns over a worldwide shortage were voiced.

As the situation evolved the organisation developed seven guidelines developing teams to guide staff and patients. These teams addressed the following needs: patients' communication and documentation; COVID19 positive patients requiring surgery; trainees' oversight and independent procedural/care guidelines; nasopharyngeal and aerosol generating procedures; physicians and providers redeployment strategy; COVID-19 perioperative evidence review; and surgical telemedicine.

The number of COVID-19 positive cases across the system in March was 179 cases of which 85 cases were admitted to the intensive care unit. Events across the Atlantic suggested that an increase in demand on ICU 
care is to be expected. The organisation asked for volunteers to be redeployed to frontline services including emergency department and ICU. The cardiothoracic surgery clinical team skill set, meant that as a team we were most suited to support our ICU colleagues.

The American College of Surgeons published guidelines for triaging elective surgery. At Emory all elective surgeries were postponed. Time sensitive surgeries were scheduled if they met any of the following criteria: the procedure is required for the patient's discharge, the procedure can be done with a very small likelihood of postoperative admission, or the procedure is required to avoid a re-admission to hospital. Procedures not meeting these criteria, as most cardiothoracic urgent procedures, had to go through an adjudication process. A site-specific surgeon adjudicator, site nurse-in-charge, and site anaesthetist carried out the adjudication. Elective activity was only resumed at a quarter of the normal capacity by May, and we resumed our usual level of activity by June. To date, all patients undergoing elective or urgent surgery are screened within 48 hours of their procedure. We certainly identified COVID-19 positive patients and these cases were postponed.

Telemedicine took a centre stage during the pandemic with an increase in utilisation ${ }^{(4)}$. Initially, all outpatient consultants were cancelled. When it became clear that the pandemic is going to last for few more months, a move to on-line and phone consultations took place. The use of web-cameras and online consultations became familiar to most providers very quickly. To this date, as in-person outpatient appointments are resumed, some patients still prefer on-line consults.

Emory's Vaccine and Treatment Evaluation Unit (VTEU) was also involved in a phase 1 trial evaluating a vaccine for COVID-19, that was in addition to a rich portfolio of academic activities centred around the pandemic. Staff were encouraged to identify research areas related to their speciality or contribute to on-going research projects.

\section{How were patients affected?}

Certainly, the pandemic created a lot of anxiety in the population, including avoidance of seeking medical help when it is desperately needed; the most worrisome was the data from New York as the number of patients presenting with acute coronary syndrome dropped by around $40 \%^{(5,6)}$. Surgeons had to deal with late presentation of diseases, such a post infarct ventricular septal defects and papillary muscle rupture. The psychological impact is equally pronounced from major depression to anxiety ${ }^{(7)}$.

Emory visitation policy, which still stands in September 2020, meant patients cannot have visitors apart from very exceptional circumstances. The aim of the policy was to protect patients and staff. Some of our patients elected to postpone their surgeries, some of which died while waiting for the pandemic to pass; others died postoperative alone on a hospital bed.

\section{Training in cardiac surgery during the epidemic:}

Cancellation of elective surgery and outpatient activities was bound to affect training in cardiothoracic surgery. Furthermore teaching sessions, conferences, and courses were cancelled because of the pandemic. Residents created a COVID work-schedule. The schedule was made to ensure that the minimum number of residents are at work at a given point, that allowed for equal distribution of training opportunities in the operating room. The gap created by lack of elective activities was filled by a twice daily virtual didactic teaching sessions. Redeployment to other services was also discussed and a schedule of residents available to support ICU team was made. The number of cases logged by residents in the period March-May was minimal, but a different type of learning took place, more suited for the times and more purposeful. As the elective workload returned towards normality, the virtual teaching sessions reduced in frequency. The COVID work schedule lasted until May and residents resumed their usual work pattern by June. Clearly, they effect of the pandemic was pronounced on training opportunities but residents like other staff groups demonstrated adaptability to the times and rose to the challenges.

\section{Conclusion:}

The COVID-19 pandemic affected the world in a way no one imagined. In cardiothoracic surgery both 
patients and staff had to bear the consequences. It is with resilience and adaptability across the organisation that we probably managed to pull through the worst period in this pandemic. Lessons have been learned and we look for a better future for our speciality and the patients we serve.

\section{Author's contribution:}

Eltayeb Mohamed Ahmed prepared the manuscript and revised the final manuscript.

Edward P Chen prepared the manuscript and revised final manuscript

\section{References:}

1. Almaghaslah D, Kandasamy G, Almanasef M, Vasudevan R, Chandramohan S. Review on the coronavirus disease (COVID-19) pandemic: its outbreak and current status. Int J Clin Pract. 2020:e13637.

2. Adhikari SP, Meng S, Wu YJ, Mao YP, Ye RX, Wang QZ, et al. Epidemiology, causes, clinical manifestation and diagnosis, prevention and control of coronavirus disease (COVID-19) during the early outbreak period: a scoping review. Infect Dis Poverty. 2020;9(1):29.

3. Harcourt J, Tamin A, Lu X, Kamili S, Sakthivel SK, Murray J, et al. Severe Acute Respiratory Syndrome Coronavirus 2 from Patient with Coronavirus Disease, United States. Emerg Infect Dis. 2020;26(6):1266-73.

4. Kichloo A, Albosta M, Dettloff K, Wani F, El-Amir Z, Singh J, et al. Telemedicine, the current COVID19 pandemic and the future: a narrative review and perspectives moving forward in the USA. Fam Med Community Health. 2020;8(3).

5. Joshi S, Kazmi FN, Sadiq I, Azemi T. Post-MI Ventricular Septal Defect During the COVID-19 Pandemic. JACC Case Rep. 2020;2(10):1628-32.

6. Braiteh N, Rehman WU, Alom M, Skovira V, Breiteh N, Rehman I, et al. Decrease in acute coronary syndrome presentations during the COVID-19 pandemic in upstate New York. Am Heart J. 2020;226:147-51.

7. Sljivo A, Kacamakovic M, Quraishi I, Dzubur Kulenovic A. Fear and Depression among Residents of Bosnia and Herzegovina during COVID-19 Outbreak - Internet Survey. Psychiatr Danub. 2020;32(2):26672 . 